\title{
A View of Spirituality and Spiritual Care in a Sample of Spanish Nurses
}

\author{
Abilio Reig-Ferrer, Carmen de la Cuesta-Benjumea $\mathbb{D}$, María Dolores Fernández-Pascual *(D) \\ and Ana Santos-Ruiz \\ Department of Health Psychology, Faculty of Health Sciences, University of Alicante, 03080 Alicante, Spain; \\ areig@ua.es (A.R.-F.); ccuesta@ua.es (C.d.1.C.-B.); anasantos@ua.es (A.S.-R.) \\ * Correspondence: mariadolores.fernandez@ua.es
}

Received: 13 November 2018; Accepted: 19 February 2019; Published: 22 February 2019

\begin{abstract}
The aim of this paper was to explore a select group of Spanish nurses' views of spirituality and spiritual care. An exploratory design using both qualitative and quantitative methods was used in this study. The participants were nurses who were enrolled in a Master of Nursing Research. Data were collected via an open questionnaire. Furthermore, participants completed the Meaning in Life Scale (MiLS-Sp), whose results were analysed using quantitative methodology. The results that were obtained from the quantitative analyses reported a satisfactory mean score on nurses' self-reported spirituality. Qualitative data were analysed using grounded theory procedures. Qualitative analysis showed two approaches to spirituality nurses' views: (i) a clinical approach that influenced by the context of their clinical practice and (ii) an alternative approach where spirituality was viewed as a health resource, moving away from the biomedical model of nursing training. Nurses are sensitive to spirituality issues and acknowledge their importance to practice. Despite this, they view spirituality in a rather mechanistic way without changing their attitudes, competences and perspectives on healthcare.
\end{abstract}

Keywords: Meaning in Life Scale; nursing; spirituality; qualitative analysis

\section{Introduction}

Since Florence Nightingale, spirituality has become a focus for nursing theory and practice (Jaberi et al. 2017; Ku 2017; Pike 2011; Timmins et al. 2015) and patients' spiritual needs have been acknowledged in policy documents (McSherry 2016). Nurse educators are increasingly being asked to cover this issue in teaching (Cone and Giske 2013; Galloway and Hand 2017) and scholars have introduced spirituality into their nursing care models and made it the cornerstone of holistic nursing care.

Despite this increased interest, literature that is related to spirituality in nursing education is scarce. The lack of attention to spirituality in the undergraduate curriculum is often cited by nurses in practice (Tiew et al. 2013; Timmins et al. 2015).

The role of spirituality in nursing and in the health sciences has been the object of recent literatures reviews (Pirkola et al. 2016) which reflects the relevance of this topic for nursing today. This interest in the nursing literature is triggered by the realization that holistic patient care ought to include spiritual care. However, despite this interest, little is known regarding nursing providers' own views on spirituality and how relevant these views may be for their practice. This study describes nurses' views about the meaning of spirituality for them, as well as spirituality in patient care. Understanding nurses' views of spirituality, their role in spiritual care and the challenges of integrating spiritual care into patient care has important implications for nurses' education. 


\subsection{Background}

Much has been written regarding the importance of spirituality in nursing care. In spite of a proliferation of research indicating it, a few systematic studies or literature reviews (McBrien 2010; Musgrave and McFarlane 2003; Terceño-López et al. 2017; Timmins and Caldeira 2017) have been conducted to show how nurses perceive spirituality and spiritual care. At the national level, few studies in Spain have been conducted on this topic (Ballesteros et al. 2014). The reasons for this may be that the majority of studies on spirituality address the spirituality of patients (Fombuena et al. 2016; Jimenez-Fonseca et al. 2018).

If we accept that nurses' work is spiritual in nature, then we must also accept that nurses have a need for continued sustenance of their spiritual requirements. The spiritual needs of the practicing nurse are not typically evaluated or addressed (Koren and Papadimitriou 2013) but fortunately there is emerging recognition of the spiritual needs of nurses.

The literature underscores the difficulties that nurses have in expressing what spirituality is and the contextual difficulties they face in addressing spirituality with their patients (Molzahn and Sheilds 2008). Part of the challenge is that nurses may confuse spirituality with religious beliefs and refer this aspect of care to other professionals' groups (Pike 2011; Timmins and Caldeira 2017). This lack of nurses' knowledge about the spiritual dimension as an integral part of nursing care can result in a failure to deliver holistic nursing care (Ozbasaran et al. 2011).

Spirituality is a difficult concept to define, and this results in a limited critical engagement and exploration of the concept itself (McSherry and Jamieson 2013; Rudolfsson et al. 2014), thus making theoretical development and measurement difficult. Numerous definitions of spirituality have been proposed. In their position statement on Spirituality, Health and Nursing Practice, the Canadian Nurses Association defines spirituality as whatever or whoever gives ultimate meaning and purpose in one's life that invites particular ways of being in the world in relation to others, oneself and the universe (Canadian Nurses Association 2010).

Spirituality is also seen as a worldview that integrates, connects, transcends and gives meaning to life. Previous empirical evidence (Van Tongeren et al. 2015; Yalçın and Malkoç 2015) has substantiated that meaning in life is related to subjective well-being through forgiveness and hope. These studies suggest that increased meaning in life predicted greater forgiveness. In this study, the definition of spirituality incorporates these elements as they relate to nurses' own worldview. For nursing care, we agree with authors who suggest that spiritual nursing care is an intuitive, interpersonal, altruistic, and integrative expression that is contingent on the nurse's awareness of the transcendent dimension of life that reflects the patient's reality (Ramezani et al. 2014).

Although the literature frequently mentions the Biopsychosocial-Spiritual Model as a way of providing holistic and quality patient care (Cairns 2012; Puchalski et al. 2014), there is growing evidence to indicate that spiritual well-being, or spiritual quality of life, is a distinctive and independent concept in assessing the quality of life (Skevington et al. 2013).

\subsection{Aim}

The aim the study was to explore a select group of Spanish nurses' views of spirituality and spiritual care.

\section{Method}

\subsection{Study Design and Participants}

This study used an exploratory design using both qualitative and quantitative methods.

A convenience sample of 25 nurses was invited to participate in this study and the response rate was $80 \%(\mathrm{~N}=20)$. The participants were recruited from students that were enrolled in the Master in Nursing Research in 2014. 


\subsection{Data Collection}

Data were collected via an open questionnaire. Furthermore, the participants completed the Spanish version (Reig-Ferrer et al. 2012, 2015) of the Meaning in Life Scale, MiLS (Jim et al. 2006), whose results were analysed using quantitative methodology.

Demographic information relating to age, marital status, educational level and current occupation was obtained and the MiLS-Sp was administered by one researcher.

\subsubsection{The Meaning in Life Scale (MiLS-Sp)}

The MiLS-Sp evaluates the concept of spirituality as meaning in life using 21 different questions in four different dimensions. The four different categories of the MiLS questionnaire are consistent with rigorous theoretical models (Jim et al. 2006) and they incorporate the most essential areas regarding self-transcendence and external transcendence: (1) Life perspective, purpose, and goals (seven items; e.g., 'I feel more fulfilled and satisfied with life', 'I am settled about the future') measures the level of personal fulfilment and satisfaction with life felt by the person in his/her current personal situation and reflects the person's level of commitment with activities, self-comprehension, and optimism for the future; (2) Confusion and lessened meaning (seven items; e.g., 'I get confused when I try to understand life', 'Life has less meaning') a scale indicating the loss or decrease in the value and worth of life, in terms of a loss of motivation to perform important functions, a sense of confusion regarding sense of self and life in general, and the belief that life is a negative experience; (3) Harmony and peace (four items; e.g., 'I feel peaceful', 'I can reach into myself for comfort') scale that evaluates the level of inner peace and harmony, self-forgiveness, personal equilibrium, the experience of an inner feeling that provides happiness and a positive outlook, which establishes a sense of tranquillity, serenity, and comfort; and, (4) Benefits of spirituality (three items: e.g., 'I find comfort in my faith and spiritual beliefs', 'I have strength in my spiritual beliefs') evaluates the level of strength, fortitude, and consolation that religious faith or other spiritual beliefs that fall outside of a traditional religious framework may provide. The items referred to illness of MiLS questionnaire were adapted to healthy subjects, for example, 'my current health status has strengthened my faith or spiritual beliefs'.

Scores that were obtained in MiLS-Sp must be considered according to the results of a reference group of 242 nursing students. This group presented normalised media scores of 6.3 for Purpose, 2.3 for Lessened meaning, 6.5 for Peace, 3.4 for Benefits of Spirituality, and 6.5 for the total score for spirituality. Other psychometric properties of the MiLS-Sp are available in Table 2.

\subsubsection{The Open Questionnaire}

To explore participants' views of spirituality and spiritual care in a clinical setting, an open questionnaire self-administered was used. Due to the reflective nature of writing, the participants were invited to write about the meaning that spirituality has for them and its relevance to practice (Table 1). Participants answered the open questions at home, in the period of one week. After that, they returned the questionnaire to the researchers.

Table 1. Open Questions.

\begin{tabular}{cc}
\hline Number & Question \\
\hline 1 & Your spiritual well-being considering the intrapersonal, interpersonal and transpersonal \\
2 & dimensions. \\
3 & If your own spirituality can be useful for the holistic care of patients with spiritual needs \\
4 & The relevance of specific education to detect and respond to spiritual needs of specific patients. \\
\hline
\end{tabular}

Data saturation was considered to be achieved when data collection reported no new information and attained an appropriate level of interpretation. 


\subsection{Ethical Considerations}

The study protocol was approved by the Ethical Committee of the University of Alicante, Spain. All of the responses were treated anonymously and confidentially and all data were stored securely.

\subsection{Data Analysis}

Qualitative and quantitative analyses were conducted. Quantitative data were analysed using the SPSS version 24. The corresponding descriptive statistics for the different variables that were analysed in the study were calculated. Cronbach alpha coefficients were calculated for the full global spirituality scale and each of its four subscales to examine the internal reliability of the scale.

Qualitative data were analysed in three stages following well-established coding procedures in Grounded Theory (Corbin and Strauss 2008) and using the constant comparison analysis. First, an open coding of the answers was carried out and the data were segmented into discrete parts. These segments were abstracted under conceptual headings. Second, these headings were grouped into categories and an analysis to identify the relationships between them and to identify patterns was made. Finally, the themes were established at a high level of abstraction and the selective coding was completed in relation with the research questions, allowing for the emergence of new themes. A total of 200 codes were produced and, through a process of constant comparison, were assembled into categories and subcategories. The analysis was made by a researcher and subsequently agreed by the research team.

\section{Results}

This section is structured as follows. In Section 3.1, we describe the results of the analysis of the descriptive data that were obtained from the survey included MiLS-Sp scores and sociodemographic details for the respondents. Section 3.2. shows the findings of qualitative questionnaire data.

\subsection{Quantitative Results}

\subsubsection{Participants' Characteristics}

The age of participants ranged from 21 to 65 years, with an average age of 35.80 (SD = 13; median $=36$ ) years. The majority of the participants were female $(75 \%)$ nearly half were married $(45 \%)$ and more than half did not have children (65\%). All of the nurses had more than one year of clinical experience in a Spanish public hospital. Nearly two-thirds $(65 \%)$ enjoyed a good or very good financial status and $70 \%$ were employed. When it came to religion, $15 \%$ were practising Catholics, $45 \%$ were Catholics but did not practice, $5 \%$ practised other religions, $20 \%$ considered themselves agnostic, and $15 \%$ said they were atheists.

\subsubsection{Analysis of Meaning in Life Scale (MiLS-Sp) Data}

Table 2 displays and summarises the different scales of the MiLS-Sp questionnaire with Cronbach's alpha, Test-retest reliability and the standardised score. Alphas for the scales ranged from 0.84 to 0.91 with a value of 0.93 for the total score and the two-week test-retest reliability was 0.79 for the total score. 
Table 2. Descriptive analysis of the Meaning in Life Scale (MiLS-Sp) ${ }^{\dagger}(n=20)$.

\begin{tabular}{ccccc}
\hline & $\begin{array}{c}\text { Standardised * Score } \\
(\mathbf{m i n} \mathbf{0 - 1 0} \text { max) }\end{array}$ & $\begin{array}{c}\text { Cronbach's } \\
\text { alpha }(\boldsymbol{\alpha})\end{array}$ & $\begin{array}{c}\text { Cronbach's } \\
\text { alpha }(\boldsymbol{\alpha})\end{array}$ & Test-Retest **** \\
\hline Purpose & $6.7(3.1-9.7)$ & 0.912 & 0.857 & 0.76 \\
Lessened meaning & $2.1(0-6)$ & 0.844 & 0.850 & 0.81 \\
Peace & $6.5(1.9-9.4)$ & 0.838 & 0.844 & 0.75 \\
Benefits of Spirituality & $5.3(0-8.3)$ & 0.789 & 0.906 & 0.72 \\
Total score for Spirituality (MiL) & $6.9(3-9.5)$ & 0.939 & 0.927 & 0.84 \\
\hline
\end{tabular}

Note: * Standardised score: (mean-minimum value/maximum value-minimum value) $\times 10 .{ }^{* *}$ Cronbach's alpha $(\alpha): \mathrm{n}=20$ nurses. ${ }^{* * *}$ Cronbach's alpha $(\alpha): \mathrm{n}=242$ nursing students. ${ }^{* * * *}$ Test-retest: $\mathrm{n}=82$ nursing students (15 days between test and retest). ${ }^{\dagger}$ MiLS-Sp: Meaning in Life Scale. MiL: Meaning in Life.

The standardised scores, transformed to a scale of 0 to 10, varied from 2.1 (Confusion and lessened meaning) to 6.7 (Life perspective, purpose and goals). The normalised mean score for the spirituality questionnaire was 6.9. In other words, these nursing professionals reported a satisfactory mean score on their perception of their own spirituality. However, there were professionals that scored below 5, specifically two nurses (15\%) with scores of three, which indicates a lower meaning of life. On the other hand, a larger group of professionals (30\%) obtained a score of eight or above.

\subsection{Qualitative Findings}

The meaning of spirituality, spirituality in practice, and the context of spirituality were the emerging categories from the open questionnaire. Below each is presented with the illustrative individual reflection $(\mathrm{R})$.

\subsubsection{The Meaning of Spirituality}

For the participants in the study, the main characteristic of spirituality was that it was not something that could be physically grasped; nor was it easily perceived. As one participant said, the concept is difficult to define, make it operational and measurable (R10). The concept, for participants is mostly ethereal. As another nurse said: Regarding the nature of spirituality, it is difficult to express it in words, it is an intangible concept. (R4)

Although the concept is difficult for nurses to precisely define, they could feel its presence in a positive way. Participating nurses regarded spirituality as a resource for health. It can be beneficial for patients, for providing health care and promoting personal growth. Participants made it clear that spirituality was not equivalent to religiosity, but most of them spontaneously declared their position that covered practically all of the spectrum, from saying they were agnostic, to believers, religious persons and finally Catholic. This suggests an implicit relationship between spirituality and religion in participants' meaning of spirituality.

The nurses referred to spirituality as a complex concept, present on occasions (R14), and with great inter- and intrapersonal variability depending on each person and the circumstances. In addition, they recognised that there were multiple ways to find it, such as through religion, music, art or via our principles and values (R5). It is not surprising that participants viewed spirituality as a problematic concept in practice as, for them, it has great variability, many different sources, and no clear limits. One nurse plainly said: We do not know the limits of the definition of spirituality (R10).

Nevertheless, when participants referred to clinical practice in their accounts, spirituality was addressed by using the metaphor of sphere (esfera); which is something round, tangible, and related to holistic nursing care, an approach that considers all the different parts that make up human beings. Although it is useful that spirituality can be symbolised with concepts and words that underline a practical approach, the danger is to view it as simply something that ought to be incorporated into the clinical setting without any change. Or as one participant stated (R9): 
The biomedical model that we had before was more hegemonic-the physical and pathological aspects of the body were the most important. These days that model is not used as much. The bio-psycho-social model has taken over from the biomedical model and social, psychological and mental aspects are as important as the physical. To this we must add the spiritual sphere. That is now a necessity and very important and is beginning to be considered. [in clinical practice]

Indeed, the metaphor of the sphere or component indicates something that can be divided and separated with no interaction with other different parts, in this case, those that make human beings, and can therefore be easily added to them.

\subsubsection{Spirituality in Practice}

Two approaches surfaced when participants explored and discussed the relevance of spirituality to nursing practice. One focussed on clinical treatment, greatly influenced by the context of the hospital that regards spirituality as a kind of health deficit, and the other, an alternative approach that saw spirituality as a human strength that is intrinsic to the person. Finally, participants placed spirituality in the context of the end of life, as it is truly relevant for them in that situation.

\section{A Clinical Approach: Spirituality as a Need to Be Met}

The clinical approach predominates in the participants' responses. Accounts that were generated by this study are full of clinical language, such as signs of, detection (R8, R9), diagnosis (R5) and therapy (R16), and spirituality are regarded as needs that ought to be met by clinical means. Thus, the diagnosis or detection of spiritual needs is emphasised in their writings. The ethereal nature of spirituality and its complexity, expressed by participants earlier, has now given way to discussing instrumental ways of detecting and supplying patients' spiritual needs in the same way that their physical needs are being cared for. Hence, patients are regarded as passive and with spiritual deficits, the professional is the one who intervenes to make things better. A participant sums it up (R9):

...the professional ought to be able to detect patients' needs. Sometimes we have signs that objectively show that the person has a spiritual need and we are not always going to be able to meet this need or see it met by someone else.

In this approach, spiritual needs are shortfalls, health deficits that professionals ought to detect and respond to. However, interventions are not specified within this approach. Participants just mentioned the general and ambiguous term of covering needs and, when appropriate, the intervention was making a referral to a specialist to deal with the previously identified spiritual need. In this approach, spirituality is personal, focussed on treatment, and out of context; it follows a disease-oriented model, a model that still dominates clinical practice. This way of approaching spirituality in practice greatly contrasts with nurses' understanding of spirituality and the meaning they attach to spirituality, as discussed earlier.

Consistent with this approach is the understanding that is held by participants that nursing education must mostly provide the tools and means to meet patients' spiritual needs. For instance, one participant wrote that education must permit the acquisition of skills in the appropriate tools (to detect spiritual needs) (R16) and another pointed out to the need for training in certain techniques (to cover spiritual needs) and for the provision of certain tools (to respond to patients' spirituality) (R9). Participants' view of spirituality is mostly instrumental and, for some, as stated in their accounts, it must be an area of specialisation in nursing.

The context of the hospital and the way that it conditions spiritual encounters and development is omitted in the participants' accounts. Additionally, they do not consider any action that would meet patient's needs and promote their spirituality while in hospital. This is a conspicuous omission, as the creation of therapeutic environments has been present since the early days of nursing. Despite being 
mentioned in the accounts, the relevance of relationships for spirituality is not addressed in the clinical setting. In this approach, spirituality is individualistic, focussed in treatment, and decontextualized.

An Alternative Approach: Spirituality as a Human Strength

Within this alternative approach, spirituality is perceived as a strength that is present in every human being. Patients are not passive but are viewed in the accounts as agents of their own spirituality, who can verbalise, explore, and uncover their spiritual needs and have the resources to meet them. The nurse's role here is framed as a therapeutic relationship: the nurse listens, enables, orients, interprets, helps and supports patients to meet their needs and spiritual goals. Nurses become instruments themselves, their qualities and own capacity are used to support patients' spirituality. In this approach, participants underscored the importance of being aware of, and the need to develop, their own spirituality. Education is consistently viewed here as reflexive, with spiritual experience being included and personal spirituality cultivated (R1). The assessment and intervention tools that are mentioned in the clinical approach no longer have their leading role, but the emphasis is now on the interaction of the nurse-patient relationship. As one participant said (R14):

We ought to be provided with basic training to interview patients in such areas as the emphatic encounter, active listening and open questioning in a context of counselling, silences, respect, closeness, verbal tones and eye contact.

The traditional clinical intervention is cast away and, in this approach, the patient truly becomes the centre of care, with nurses being viewed as facilitators of the patients' spirituality.

\subsubsection{The Context of Spirituality}

Spirituality in nursing practice is usually associated with the end-of-life situations, related to both patients' and nurses' lives. One nurse wrote: many times I though what I would do if someone told me that I was about to die (R6). The references to death, the process of dying and palliative care are abundant in participants' accounts. It seems that these are the circumstances where spirituality has the most meaning and relevance for nurses:

[spirituality is relevant] in palliative care, hospital oncology service and intensive care units-places where death is constantly present. (R10)

A wider health context is also mentioned in some accounts. For some, spirituality is relevant for patients in general, not only in end-of-life circumstances, but also in other important life events, such as giving birth. However, these thoughts are marginal. What dominated the nurses' writings in this area of spirituality in practice was a context of loss and terminal care. It seems that for the nurses spirituality and the end of life go together.

\section{Discussion}

This study aimed to explore a select group of Spanish nurses' views of spirituality and spiritual care in clinical settings.

Quantitative findings indicate that participants were aware of, and satisfied with, their own spirituality, as reflected by the MiLS-Sp scale scores. These findings are consistent with other data obtained from groups of nursing students (Reig-Ferrer et al. 2017). The degree of perceived and manifested spiritual well-being of this group of nurses is significantly higher when compared with other Spanish patient groups, such as patients with cancer, renal diseases (Reig-Ferrer et al. 2012), and in palliative care (Reig-Ferrer et al. 2015).

Studies, to date, have shown moderate levels of spiritual wellbeing for both Nursing students and nurses (Ross et al. 2018; Tiew et al. 2013). Results show that, despite scoring moderately on spirituality, as measured by the MiLS-Sp questionnaire, the nurses had difficulty defining the concept itself and differentiating spirituality from other terms, such as religiosity. This could be explained 
by the difference between providing a measure of spirituality that is based on a theoretical model (through MiLS-Sp) or otherwise presenting open questions without a reference model. It is easier to respond to a questionnaire that is based on a theoretical model and adjusting to that model than to answer open queries without a frame of reference. In that latter case, where nurses had no a clear concept of spirituality, they respond by establishing relationships with other concepts that are popularly related to, such as religiosity. As mentioned by Weathers et al. (2016) in their spirituality concept analysis, religiosity is the main concept that is spirituality related to in the literature, although there are an increasing number of researchers studying the difference between spirituality and religiosity (Barker and Floersch 2010). Another interesting concept that is related to the study of spirituality is the concept of forgiveness. It would be interesting to explore in future studies the spiritual dimensions that play an important role in the evaluation of forgiveness.

When confronted by the issue of spirituality in their practice, qualitative findings show that spirituality became a source of confusion for participants. In relation to the meaning of spirituality, they found it difficult to define spirituality and to separate it from a spiritual care situation or episode, as has been reported in other studies (Dagha 2018; Giske and Cone 2015). A review of the literature confirmed that nurses are aware of their lack of knowledge, understanding, and skills in the area of spirituality and spiritual care, and they desire to be better informed and skilled in this area (Lewinson et al. 2015; Timmins and Caldeira 2017). However, specific spiritual activities that nurses can undertake are not clearly outlined in nursing textbooks and few of the required spiritual care nursing competencies are explicated in these textbooks (Timmins et al. 2015).

The vagueness and ambiguity in the meaning of spirituality has also been pointed out in the literature (Nahardani et al. 2018; Pike 2011; Reinert and Koenig 2013), together with a question as towhether the concept can be fully grasped. Weathers et al. (2016) analysed the evolution the concept of spirituality, including findings from quantitative and qualitative researches and concluded that operational definitions of spirituality should include the three dimensions of transcendence, connectedness, and meaning in life, as approached in our study. The results of our study show that nurses seem to have a poor language to tackle patients' spiritual concerns and they resorted to the familiar clinical language to address them. It has been suggested that the "divorce" of spirituality from religion has left nurses with limited language that is separated from the language of their patients (Clarke 2009). Accounts in our study also reflected the terminology used in the literature, which invites an instrumental intervention stance to deal with patients' spirituality (Pike 2011).

When spirituality is situated in practice, some participants viewed it in two ways; as a need to be met and as a human strength. Thus, for most study participants, the meaning of spirituality is linked to the clinical gaze, which is consistent with symbolic interactionism that views meaning as emerging from the action/interaction (Blumer 1969). Previous studies have voiced the intangible nature that spirituality has for nurses and nursing practice (Shores 2010), and have also established that nurses work in a practice context that does not promote spiritual care (Minton et al. 2018). Similarly, participants of this study omitted the context of the hospital and the way that it conditions spiritual encounters in their responses.

Regarding the functionality of spirituality, some study participants saw spirituality as a strength that is present in every human being. Literature supports the positive psychology view and underscores the need to regard spirituality as a means for nurses' personal growth and as a resource for their own practice. Indeed, as health professionals' awareness of their own spirituality improves so does their ability to deliver spiritual care (Baldacchino 2011).

Finally, this study reported that nurses tend to have a restricted view of spirituality by frequently linking it to the end of life, circumstances in which, certainly, spiritual care is provided by nurses, as mentioned by some authors (Ronaldson et al. 2012).

To link the meaning of spirituality to the end of life might also account for nurses' need to contextualize spirituality in a manner to support its application in practice (Pike 2011). It seems that a psycho-pathological gaze dominates nurses' views on spirituality. The clinical setting accounts 
for this approach and limits nurses' scope of action. The nursing literature also plays a role here. It has been argued that, by focusing on a select set of specialties, spirituality has a minor place in nursing. The shortcomings of defining spirituality in a relevant way for nurses, the lack of conceptual clarity, and the use of a specialized language away from patients' own experiences (Clarke 2009; Pirkola et al. 2016) might also contribute to the domination of this psycho-pathological gaze in practice.

\section{Limitations}

Some important limitations of the study must be mentioned.

Firstly, relying on a single method of collecting qualitative material limits the scope of the findings, and the self-reported accounts, while reflective, limits the richness of data as researchers could not ask for further elaborations and details. This limitation suggests additional paths for further research into the issue of spirituality and nursing practice.

Secondly, given the small sample size the current study does not allow the generalisation of results to the whole nursing population.

Furthermore, the MiLS questionnaire has originally be developed and validated for patient populations.

Finally, another possible limitation of the study is the disparity in numbers of male and female participants. However, this is a frequent occurrence in studies with nurses.

\section{Conclusions}

Our study shows that nurses are sensitive to spirituality issues and they acknowledge their importance to practice. Participants' views of an alternative approach to the clinical approach to spirituality suggest that nursing education programs should include information on spirituality that reinforces a change in nursing outlook. Nursing educators must pay attention to the fact that spirituality could be viewed in a rather mechanistic way, as something that just needs to be added to nursing practice without changing attitudes and perspectives on healthcare. In order to advance and develop spirituality in nursing practice, the findings suggest that nurse educators should consider the role that the working context has on spirituality and the role that other health professionals can play on promoting or in inhibiting it. As symbolic interactionism states, meaning derives from the action interaction, from the clinical setting in our case.

The views on spirituality that are revealed in this paper can help nurses to become aware of the meaning that they attach to spirituality and consider the different approaches used in practice. Further studies exploring practitioners' views on spirituality and barriers to effective spiritual care in clinical settings are needed. These studies could give grounds to support nurse educators' efforts in promoting spiritual care among students and clinicians.

Author Contributions: A.R.F. designed and guided the research. A.R.F and C.C.B. wrote the article and did the final version. All the authors contributed substantially to collect and analyses data, contributed in the discussion of the results and reviewed the draft.

Funding: This research received no external funding.

Acknowledgments: The authors are grateful to all participants in this study for their outstanding collaboration. In addition, the authors would like to thank the opportunity to discuss central issues of this work in the 6th European Conference on Religion, Spirituality and Health, May 2018.

Conflicts of Interest: The authors declare no conflict of interest.

\section{References}

Baldacchino, Donia R. 2011. Teaching on spiritual care: The perceived impact on qualified nurses. Nurse Education in Practice 11: 47-53. [CrossRef] [PubMed]

Ballesteros, Montserrat, Carlos Centeno, and Maria Arantzamendi. 2014. A qualitative exploratory study of nursing students' assessment of the contribution of palliative care learning. Nurse Education Today 34: e1-e6. [CrossRef] [PubMed] 
Barker, Stacey L., and Jerry E. Floersch. 2010. Practitioners' understandings of spirituality: Implications for social work education. Journal of Social Work Education 46: 357-70. [CrossRef]

Blumer, Herbert. 1969. Symbolic Interactionism. Perspective and Method. Englewood Cliffs: Prentice-Hall.

Cairns, Will. 2012. Science relocating spirituality into the bio-psycho-social. Palliative Medicine 26: 187. [CrossRef] [PubMed]

Canadian Nurses Association. 2010. Position Statement: Spirituality, Health, and Nursing Practice. Ottawa: Canadian Nurses Association.

Clarke, Janice. 2009. A critical view of how nursing has defined spirituality. Journal of Clinical Nursing 18: 1666-73. [CrossRef] [PubMed]

Cone, Pamela H., and Tove Giske. 2013. Teaching spiritual care-A grounded theory study among undergraduate nursing educators. Journal of Clinical Nursing 22: 1951-60. [CrossRef] [PubMed]

Corbin, Juliet, and Anselm Strauss. 2008. Basics of Qualitative Research. Techniques and Procedures for Developing Grounded Theory, 3rd ed. London: SAGE.

Dagha, Safak. 2018. Nursing students' perceptions of spirituality and spiritual care; an example of Turkey. Journal of Religion and Health 57: 420-30. [CrossRef]

Fombuena, Miguel, Laura Galiana, Pilar Barreto, Amparo Oliver, Antonio Pascual, and Ana Soto-Rubio. 2016. Spirituality in patients with advanced illness: The role of symptom control, resilience and social network. Journal of Health Psychology 21: 2765-74. [CrossRef]

Galloway, Sharon, and Mikel W. Hand. 2017. Spiritual Immersion: Developing and Evaluating a Simulation Exercise to Teach Spiritual Care to Undergraduate Nursing Students. Nurse Educator 42: 199-203. [CrossRef]

Giske, Tove, and Pamela H. Cone. 2015. Discerning the healing path-How nurses assist patient spirituality in diverse health care settings. Journal of Clinical Nursing 24: 2926-35. [CrossRef]

Jaberi, Azita, Marzieh Momennasab, Shahrzad Yektatalab, Abbas Ebadi, and Mohammad Ali Cheraghi. 2017. Spiritual Health: A Concept Analysis. Journal of Religion and Health, 1-24. [CrossRef] [PubMed]

Jim, Heather S., Jason Q. Purnell, Susan A. Richardson, Deanna Golden-Kreutz, and Barbara L. Andersen. 2006. Measuring meaning in life following cancer. Quality of Life Research 15: 1355-71. [CrossRef] [PubMed]

Jimenez-Fonseca, Paula, Urbano Lorenzo-Seva, Pere Joan Ferrando, Alberto Carmona-Bayonas, Carmen Beato, Teresa García, María del Mar Muñoz, Avinash Ramchandani, Ismael Ghanem, Alejandra Rodríguez-Capote, and et al. 2018. The mediating role of spirituality (meaning, peace, faith) between psychological distress and mental adjustment in cancer patients. Supportive Care in Cancer 26: 1411-18. [CrossRef] [PubMed]

Koren, Mary Elaine, and Christina Papadimitriou. 2013. Spirituality of staff nurses: Application of modeling and role modeling theory. Holistic Nursing Practice 27: 37-44. [CrossRef] [PubMed]

$\mathrm{Ku}$, Ya-Lie. 2017. Literature Review on Spiritual Care in Nursing. Journal of Nursing and Health Studies 2: 1-4.

Lewinson, Lesline P., Wilfred McSherry, and Peter Kevern. 2015. Spirituality in pre-registration nurse education and practice: A review of the literature. Nurse Education Today 35: 806-14. [CrossRef] [PubMed]

McBrien, Barry. 2010. Emergency nurses' provision of spiritual care: A literature review. British Journal of Nursing 19: 768-73. [CrossRef]

McSherry, Wilfred. 2016. Reintegrating spirituality and dignity in nursing and health care: A relational model of practice. In Stories of Dignity within Healthcare: Research, Narratives and Theories. Edited by Oscar Tranvåg, Oddgeir Synnes and Wilfred Mcsherry. Keswick: M\&K Publishing, pp. 75-96.

McSherry, Wilfred, and Steve Jamieson. 2013. The qualitative findings from an online survey investigating nurses' perceptions of spirituality and spiritual care. Journal of Clinical Nursing 22: 3170-82. [CrossRef]

Minton, Mary E., Mary J. Isaacson, Brandon M. Varilek, Jessica L. Stadick, and Shanon O'Connell-Persaud. 2018. A willingness to go there: Nurses and spiritual care. Journal of Clinical Nursing 27: 173-81. [CrossRef]

Molzahn, Anita, and Laurene E. Sheilds. 2008. Why is it so hard to talk about spirituality? Canadian Nurse 104: 25-29.

Musgrave, Catherine F., and Elizabeth A. McFarlane. 2003. Oncology and non-oncology nurses' spiritual well-being and attitudes toward spiritual care: A literature review. Oncology Nursing Forum 30: 523-27. [CrossRef]

Nahardani, Seyedeh Zahra, Fazlollah Ahmadi, Shoaleh Bigdeli, and Kamran Soltani Arabshahi. 2018. Spirituality in medical education: A concept analysis. Medicine, Health Care and Philosophy, 1-11. [CrossRef] [PubMed]

Ozbasaran, Ferda, Safak Ergu, Ayla Bayik Temel, Gusah Gurol, and Ayden Coban. 2011. Turkish nurses' perceptions of spirituality and spiritual care. Journal of Clinical Nursing 20: 3102-10. [CrossRef] [PubMed] 
Pike, Joanne. 2011. Spirituality in nursing: a systematic review of the literature from 2006-10. British Journal of Nursing 20: 743-49. [CrossRef] [PubMed]

Pirkola, Heidi, Piia Rantakokko, and Marjo Suhonen. 2016. Workplace spirituality in health care: An integrated review of the literature. Journal of Nursing Management 24: 859-68. [CrossRef] [PubMed]

Puchalski, Christina M., Robert Vitillo, Sharon K. Hull, and Nancy Reller. 2014. Improving the spiritual dimension of whole person care: Reaching national and international consensus. Journal of Palliative Medicine 17: 642-56. [CrossRef]

Ramezani, Monir, Fazlollah Ahmadi, Eesa Mohammadi, and Anoshirvan Kazemnejad. 2014. Spiritual care in nursing: A concept analysis. International Nursing Review 61: 211-19. [CrossRef]

Reig-Ferrer, Abilio, M. Dolores Arenas, Rosario Ferrer-Cascales, Maria Dolores Fernández-Pascual, Natalia Albaladejo-Blázquez, M. Teresa Gil, and Vanesa de la Fuente. 2012. Evaluación del bienestar espiritual en pacientes en hemodiálisis. Nefrología 32: 731-42.

Reig-Ferrer, Abilio, Rosario Ferrer-Cascales, Maria Dolores Fernández-Pascual, Natalia Albaladejo-Blázquez, and Manuel Priego-Valladares. 2015. Evaluación del bienestar espiritual en pacientes en cuidados paliativos. Medicina Paliativa 22: 60-68. [CrossRef]

Reig-Ferrer, Abilio, Maria Dolores Fernández-Pascual, Ana Santos Ruiz, Julio Cabero García, Carmen de la Cuesta-Benjumea, Claudia Patricia Arredondo González, and Cristina Borrego Honrubia. 2017. Red investigación e innovación educativa en espiritualidad y cuidados de enfermería: La relación entre Personalidad y Espiritualidad en Estudiantes de Enfermería. In Memorias del Programa de Redes-I3CE de calidad, innovación e investigación en docencia universitaria: Convocatoria 2016-17. Edited by Instituto de Ciencias de la Educación. Alicante: Universidad de Alicante, pp. 1636-47.

Reinert, Katia Garcia, and Harold G. Koenig. 2013. Re-examining definitions of spirituality in nursing research. Journal of Advanced Nursing 69: 2622-34. [CrossRef]

Ronaldson, Susan, Lillian Hayes, Christina Aggar, Jennifer Green, and Michele Carey. 2012. Spirituality and spiritual caring: Nurses' perspectives and practice in palliative and acute care environments. Journal of Clinical Nursing 21: 2126-35. [CrossRef] [PubMed]

Ross, Linda, Wilfred McSherry, Tove Giske, René van Leeuwen, Annemiek Schep-Akkerman, Tiburtius Koslander, Jenny Hall, Vibeke Ostergaard Steenfeldt, and Paul Jarvis. 2018. Nursing and midwifery students' perceptions of spirituality, spiritual care, and spiritual care competency: A prospective, longitudinal, correlational European study. Nurse Education Today 67: 64-71. [CrossRef] [PubMed]

Rudolfsson, Gudrun, Ingela Berggren, and António Barbosa da Silva. 2014. Experiences of spirituality and spiritual values in the context of nursing-An integrative review. The Open Nursing Journal 8: 64-70. [CrossRef] [PubMed]

Shores, Cynthia I. 2010. Spiritual perspectives of nursing students. Nursing Education Perspectives 31: 8-11. [PubMed]

Skevington, Suzanne M., Keely Sarah Gunson, and Kathryn Ann O'Connell. 2013. Introducing the WHOQOL-SRPB BREF: Developing a short-form instrument for assessing spiritual, religious and personal beliefs within quality of life. Quality of Life Research 22: 1073-83. [CrossRef] [PubMed]

Terceño-López, Cristina, Carme Ferré-Grau, Jeroni Jurado-Campos, and María Francisca Jiménez-Herrera. 2017. A Systematic Review about Spirituality in Nursing Care: Avoiding a Specific Illness Care Environment. Journal of Advanced Practices in Nursing 2: 135.

Tiew, Lay Hwa, Debra K. Creedy, and Moon Fai Chan. 2013. Student nurses' perspectives of spirituality and spiritual care. Nurse Education Today 33: 574-79. [CrossRef]

Timmins, Fiona, and Sílvia Caldeira. 2017. Understanding spirituality and spiritual care in nursing. Nursing Standard 31: 50-57. [CrossRef]

Timmins, Fiona, Maryanne Murphy, Freda Neill, Thelma Begley, and Greg Sheaf. 2015. An exploration of the extent of inclusion of spirituality and spiritual care concepts in core nursing textbooks. Nurse Education Today 35: 277-82. [CrossRef]

Van Tongeren, Daryl R., Jeffrey D. Green, Joshua N. Hook, Don E. Davis, Jody Davis, and Marciana Ramos. 2015. Forgiveness increases meaning in life. Social Psychological and Personality Science 6: 47-55. [CrossRef] 
Weathers, Elizabeth, Geraldine McCarthy, and Alice Coffey. 2016. Concept analysis of spirituality: An evolutionary approach. Nursing Forum 51: 79-96. [CrossRef] [PubMed]

Yalçın, Ilhan, and Asude Malkoç. 2015. The relationship between meaning in life and subjective well-being: Forgiveness and hope as mediators. Journal of Happiness Studies 16: 915-29. [CrossRef] 